\title{
PEMBINAAN WANITA PENGOLAH IKAN ASIN DI PESISIR MUARA ANGKE JAKARTA UTARA
}

\section{EMPOWERMENT OF WOMEN THAT PROCESSED SALTY FISH AT MUARA ANGKE, NORTH OF JAKARTA}

\author{
Nayu Nurmalia dan Richard W.E. Lumintang
}

\begin{abstract}
Women who were involved in processing salty fish at Muara Angke, north of Jakarta, had significant contribution to their salty fish business. So far, they had never been involved in any empowerment program offered either by government institution or by non government organization. Men were mostly involved in such empowerment activities. In this conjunction, the objectives of this study were: (1) to determine the skills of the women involved in salty fish processing, (2) to identify both the internal and external factors related to the women's skills in processing salty fish, and (3) to determine the relationship intensity of the women' skills in salty fish processing and their productivity in processing such fish. The findings of the study were: the women productivity in salty fish processing was significantly related to their skills in getting qualified fresh fish, in processing and drying salty fish, in book keeping and accounting, and in getting information on marketing system.
\end{abstract}

Key words: Salty fish, Empowerment, Market system.

\section{Pendahuluan}

Pembangunan pada dasarnya merupakan upaya mencapai taraf hidup masyarakat yang lebih berkualitas sesuai dengan nilai-nilai sosial yang berlaku. Oleh karena itu proses pembangunan menuntut adanya partisipasi masyarakat yang lebih besar agar tujuan pembangunan dapat tercapai. Sumber daya manusia yang mempunyai peranan penting dalam pembangunan, salah satunya adalah wanita.

Upaya untuk memaksimalkan kemampuan yang dimiliki oleh wanita di Indonesia dalam pembangunan diawali dengan kegiatan wanita dalam memperjuangkan harkat, martabat, dan kedudukannya agar wanita dapat berperan aktif dalam pembangunan nasional. Tjokrowinoto dalam Prihatini (2000: 24) mengatakan bahwa perempuan menjadi bagian yang penting dalam pembangunan, hal ini dapat dilihat dari perannya di masyarakat dan kerja yang dilakukannya di dalam dan di luar rumah.

Keterlibatan wanita baik secara langsung maupun tidak langsung untuk ambil bagian dan bertanggung jawab dalam meningkatkan pendapatan keluarga dan produktivitas usaha pengolahan ikan asin di Muara Angke Jakarta Utara merupakan salah satu potensi penting yang perlu diberdayakan, agar dapat menunjang pendapatan keluarga. Oleh karena itu sangat diperlukan upayaupaya untuk meningkatkan keterampilan 
wanita pengolah ikan asin sehingga dapat meningkatkan produktivitas.

Mardikanto (1993) mengemukakan bahwa perumusan strategi penyuluhan pertanian juga harus diarahkan untuk meningkatkan keterlibatan kaum perempuan dan generasi muda dalam penyuluhan pertanian. Khusus yang menyangkut peningkatan peran wanita/perempuan dalam penyuluhan pertanian, perlu diperhatikan bahwa:

(1) Kaum perempuan terbukti memberikan kontribusi yang besar dalam pertanian, tetapi masih jarang dilibatkan dalam pertemuan-pertemuan penyuluhan pertanian.

(2) Kaum perempuan belum memperoleh perhatian yang sederajat dengan kaum pria, baik dalam kegiatan penyuluhan maupun dalam pelaksanaan seluruh kegiatan pertanian.

Agar materi yang disuluhkan atau dilatihkan dalam pembinaan sesuai dengan kebutuhan wanita pengolah ikan asin, maka perlu dilakukan penelitian untuk: (1) mengkaji tingkat keterampilan wanita pengolah ikan asin, (2) mengkaji materi pembinaan yang dibutuhkan oleh wanita pengolah ikan asin untuk meningkatkan keterampilan dan produktivitas usahanya.

Permasalahan penelitian ini adalah: (1) Karakteristik apakah yang berhubungan dengan keterampilan wanita pengolah ikan asin?; (2) Faktor eksternal apakah yang berhubungan dengan keterampilan wanita pengolah ikan asin?; dan (3) Apakah tingkat keterampilan wanita pengolah ikan asin berhungan dengan produktivitas usahanya?

Berdasarkan permasalahan tersebut, penelitian ini bertujuan: (1) Mengkaji hubungan antara beberapa karakteristik internal wanita pengolah ikan asin dengan keterampilannya; (2) Mengkaji hubungan antara beberapa faktor ekternal wanita pengolah ikan asin dengan keterampilannya; dan (3) Mengkaji hubungan antara beberapa tingkat keterampilan wanita pengolah ikan asin dengan produktivitas usahanya.

\section{Metode Penelitian}

Penelitian dilaksanakan pada bulan Juli sampai bulan Agustus 2005 dan penentuan lokasi dilakukan secara sengaja yaitu di Wilavah Pengolahan Hasil Perikanan Tradisional (PHPT) Muara Angke Jakarta Utara. Pertimbangan terpilihnya lokasi ini, karena PHPT Muara Angke merupakan sentra pengolahan ikan asin di Kota Jakarta.

Populasi penelitian adalah seluruh wanita pengolah yang ada di Muara Angke sebanyak 196 orang. Pengambilan sampel dilakukan dengan menggunakan metode Acak Sederhama (Simple Random, Sampling) sebanyak 50 orang wanita pengolah.

Penelitian ini merupakan penelitian deskriptif korelasional. Data primer dikumpulkan melalui wawancara dengan menggunakan kuesioner dari responden terpilih, sedangkan data sekunder dikumpulkan dari Dinas/Instansi terkait serta hasil kajian yang relevan.

Analisis data dilakukan dengan cara membuat tabulasi distribusi dari setiap variabel yang diteliti. Pengolahan data primer menggunakan bantuan software SPSS. Keeratan hubungan antara peubah (hubungan antara variabel bebas dengan variabel tidak bebas) digunakan uji korelasi peringkat Spearman (Siegel, 1997).

\section{Hasil dan Pembahasan}

\section{Karakteristik Internal Wanita PIA}

Tabel 1 menunjukkan, kisaran umur wanita PIA yang ada di Muara Angke antara 25 sampai dengan 65 tahtm. Sebagian besar (68\%) dalam kategori sedang (31 - 48 tahun). Kisaran umur tersebut tergolong umur yang produktif, artinya dari segi fisik memiliki kemampuan dalam melakukan kegiatan usaha pengolahan ikan asin. Pendidikan wanita pengolah ikan asin persentase terbesar $(76 \%)$ pada kategori sedang yaitu 4 - 7 tahun atau setingkat Sekolah Dasar. Tingkat pendidikan wanita pengolah ikan asin masih rendah ada 
yang tidak tamat Sekolah Dasar, dan pendidikan yang paling tinggi adalah tamat SMP. Rendahnya tingkat pendidikan wanita pengolah ikan asin karena umumnya menikah pada usia muda di kota kelahirannya. Pengolah ikan asin di Muara Angke sebagian besar berasal dari luar Kota Jakarta kemudian hijrah ke Jakarta untuk melakukan kegiatan usaha dan menetap di Jakarta. Jumlah tanggungan keluarga wanita pengolah ikan asin persentase terbesar kategori sedang (66\%) yaitu 5-9 orang. pengalaman usaha wanita pengolah ikan asin di Muara Angke dalam kategori sedang yaitu 8 -2l tahun. Pengalaman berhubungan dengan kepekaan seseorang untuk menafsirkan kegiatan di masa lalu dan juga merupakan salah satu tanda bahwa ia memiliki pengetahuan yang dialaminva dalam waktu yang lalu. Pengalaman usaha wanita dalam pengolahan ikan asin tergolong sudah cukup lama, hal ini berarti wanita PIA semakin banyak berinteraksi dengan pengolahpengolah yang lain dan semakin banyak berhubungan dengan pembeli.

Tabel 1. Distribusi Karakteristik Internal Wanita Pengolah Ikan Asin di Muara Angke

\begin{tabular}{|c|c|c|c|c|c|c|}
\hline No. & $\begin{array}{l}\text { Karakteristik } \\
\text { Internal }\end{array}$ & Kategori & $\mathbf{n}$ & $\begin{array}{c}\text { Persentase } \\
(n=50)\end{array}$ & Rata-rata & Interval \\
\hline 1. & Umur & $\begin{array}{l}\text { Muda (<31 tahun) } \\
\text { Sedang (31-48 tahun) } \\
\text { Tua ( }>48 \text { tahun })\end{array}$ & $\begin{array}{c}8 \\
34 \\
8 \\
\end{array}$ & $\begin{array}{l}16 \\
68 \\
16 \\
\end{array}$ & 39,64 tahun & $25-65$ tahun \\
\hline 2. & Pendidikan & $\begin{array}{l}\text { Rendah }(<4 \text { tahun }) \\
\text { Sedang }(4-7) \\
\text { Tinggi }(>7 \text { tahun })\end{array}$ & $\begin{array}{c}9 \\
38 \\
3\end{array}$ & $\begin{array}{c}18 \\
76 \\
6\end{array}$ & 5 tahun & $\begin{array}{l}2-9 \\
\text { tahun }\end{array}$ \\
\hline 3. & $\begin{array}{l}\text { Jumlah } \\
\text { Tanggungan } \\
\text { Keluarga }\end{array}$ & $\begin{array}{l}\text { Sedikit (<5 orang) } \\
\text { Sedang }(5-9 \text { orang) } \\
\text { Banyak }(>9 \text { orang })\end{array}$ & $\begin{array}{c}12 \\
33 \\
5\end{array}$ & $\begin{array}{l}24 \\
66 \\
10\end{array}$ & 6 orang & $4-11$ orang \\
\hline 4. & $\begin{array}{l}\text { Pengalaman } \\
\text { Usaha dalam } \\
\text { Pengolahan Ikan } \\
\text { Asin }\end{array}$ & $\begin{array}{l}\text { Sedikit }(<8 \text { tahun }) \\
\text { Sedang }(8-21 \text { tahun }) \\
\text { Banyak }(>21 \text { tahun })\end{array}$ & $\begin{array}{c}2 \\
43 \\
5\end{array}$ & $\begin{array}{c}4 \\
86 \\
10\end{array}$ & 14,64 tahun & $5-36$ tahun \\
\hline 5. & Motivasi & $\begin{array}{l}\text { Rendah }(<2,68) \\
\text { Sedang }(\mathbf{2}, \mathbf{6 8}-\mathbf{3 , 2 3}) \\
\text { Tinggi }(>3,23)\end{array}$ & $\begin{array}{c}6 \\
38 \\
6\end{array}$ & $\begin{array}{l}12 \\
76 \\
12\end{array}$ & 2,95 & $2,55-3,73$ \\
\hline 6. & $\begin{array}{l}\text { Kesediaan } \\
\text { Menerima } \\
\text { Informasi }\end{array}$ & $\begin{array}{l}\text { Rendah }(<1,17) \\
\text { Sedang }(\mathbf{1}, \mathbf{1 7}-\mathbf{2 , 0 5}) \\
\text { Tinggi }(>2,05)\end{array}$ & $\begin{array}{c}10 \\
36 \\
4\end{array}$ & $\begin{array}{c}20 \\
72 \\
8\end{array}$ & 1,61 & $1-3$ \\
\hline
\end{tabular}

Sebagian besar $(76 \%)$ motivasi wanita pengolah ikan asin dalam mengelola usahanya dalam kategori sedang. Hal ini menunjukkan bahwa sebagai ibu rumah tangga, wanita pengolah ikan asin dalam melakukan kegiatan usahanya mempunyai motivasi yang cukup tinggi untuk bekerja. Motivasi ini timbul dapat diakibatkan karena

Pengalaman usaha wanita pengolah ikan asin di Muara Angke antara 5 tahun sampai 36 tahun. Persentase terbesar $(86 \%)$ semakin tingginya kebutuhan hidup.

Kesediaan wanita pengolah ikan asin dalam menerima informasi teknologi pengolahan ikan asin sebagian besar (72\%) kategori sedang, hal ini menunjukkan bahwa wanita pengolah ikan asin masih mempunyai keinginan dan keterbukaan untuk menambah informasi yang berkaitan dengan usaha pengolahan ikan asin. Informasi teknologi yang diberikan oleh instansi terkait umumnya 
lebih ditujukan kepada kaum pria (suami). sehingga wanita hanya menerima informasi tersebut dari suaminya.

\section{Faktor Eksternal Wanita PIA}

Materi penyuluhan yang diterima wanita pengolah ikan asin sebagian besar pada kategori rendah dan sedang yaitu sebanyak $98 \%$. Materi penyuluhan yang berkaitan dengan teknologi pengolahan ikan asin yang diterima oleh responden masih sedikit. Selama ini materi penyuluhan teknologi pengolahan ikan asin yang diberikan oleh instansi lebih banyak diikuti oleh kaum pria, sementara para wanita hanya memperoleh informasi tersebut dari suaminya. Informasi yang diterima bila tidak secara langsung dapat terjadi gangguan (noise), sehingga tidak utuh karena tidak diperoleh langsung dari sumbernya.

Ketersediaan pasar sebagian besar berada kategori sedang sebanyak $80 \%$. Ketersediaan pasar ikan asin cukup, selama ini wanita pengolah ikan asin tidak mendapat kesulitan dalam memasarkan produknya, apabila telah ada kesepakatan harga. Secara kuantitas pasar relatif cukup, dalam arti produk yang dihasilkan para pengolah terjual. Namun demikian dari segi harga para pengolah tidak memiliki bargaining position yang tinggi. Harga lebih banyak ditentukan oleh Bandar (konsumen besar). Indikator pasar dikatakan cukup, para pengolah terus menerus melakukan aktivitas pengolahan ikan asin. Ada juga pengolah yang dibayar duluan

Tabel 2. Distribusi Faktor Eksternal Wanita Pengolah Ikan Asin di Muara Angke

\begin{tabular}{|c|c|c|c|c|c|c|}
\hline No. & $\begin{array}{c}\text { Karakteristik } \\
\text { Eksternal }\end{array}$ & Kategori & n & $\begin{array}{c}\text { Persentase } \\
(n=50)\end{array}$ & $\begin{array}{l}\text { Rata- } \\
\text { rata }\end{array}$ & Interval \\
\hline 1. & $\begin{array}{l}\text { Materi } \\
\text { Penyuluhan }\end{array}$ & $\begin{array}{l}\text { Rendah } \quad(<1.61) \\
\text { Sedang }(1.61-3.03) \\
\text { Tinggi } \quad(>3.03)\end{array}$ & $\begin{array}{c}8 \\
41 \\
1\end{array}$ & $\begin{array}{c}16 \\
82 \\
2\end{array}$ & 2.32 & $1.00-3.14$ \\
\hline 2. & $\begin{array}{l}\text { Ketersediaan } \\
\text { Pasar }\end{array}$ & $\begin{array}{l}\text { Rendah } \quad(<2.08) \\
\text { Sedang }(2.08-2.80) \\
\text { Tinggi } \quad(>2.80)\end{array}$ & $\begin{array}{c}5 \\
40 \\
5\end{array}$ & $\begin{array}{l}10 \\
80 \\
10\end{array}$ & 2.44 & $1.40-3.20$ \\
\hline 3. & $\begin{array}{l}\text { Curahan } \\
\text { Waktu Tenaga } \\
\text { Kerja }\end{array}$ & $\begin{array}{l}\text { Rendah }(<1.89) \\
\text { Sedang }(1.89-2.87) \\
\text { Tinggi } \quad(>3.38)\end{array}$ & $\begin{array}{c}7 \\
33 \\
10\end{array}$ & $\begin{array}{l}14 \\
66 \\
20 \\
\end{array}$ & 2.38 & $1.67-4.00$ \\
\hline
\end{tabular}

Curahan waktu tenaga kerja wanita pengolah ikan asin mayoritas pada kategori sedang sebanyak $66 \%$ dan kategori tinggi sebanyak 20\%. Keterlibatan wanita dalam kegiatan usaha pengolahan ikan asin di pesisir Muara Angke cukup tinggi.

Mencari bahan baku ikan mayoritas dilakukan oleh wanita pengolah ikan asin, hal ini karena wanita dianggap lebih teliti dalam mencari bahan baku ikan yang segar, selain itu wanita lebih ulet, energik dan pintar dalam (di muka), sehingga tidak dapat melakukan penawaran harga.

hal tawar menawar harga. Demikian juga dalam mencari informasi pasar, wanita pengolah ikan asin lebih gesit dibandingkan pria.

\section{Hubungan Karakteristik Internal dengan Tingkat Keterampilan}

Pengalaman usaha dan motivasi berhubungan dengan tingkat keterampilan mendapatkan bahan baku. Pengalaman usaha pengolah ikan asin berhubungan nyata 
berhubungan sangat nyata dengan keterampilan dalam mendapatkan bahan baku ikan, hal tersebut berarti semakin lama pengalaman usaha wanita pengolah ikan asin, maka semakin terampil dalam mendapatkan bahan baku ikan $(0,392 * *)$. Wanita pengolah ikan asin yang mempunyai pengalaman usaha cukup lama sangat dinamis dan energik dalam mendapatkan bahan baku ikan, baik di lokasi pelelangan ikan maupun di pelabuhan dalam negosiasi maupun tawar menawar dengan pihak produsen.

Motivasi wanita pengolah ikan asin mempunyai hubungan yang sangat nyata dengan tingkat keterampilan dalam mendapatkan bahan baku $\left(0,444^{* *}\right)$. Dalam mencari bahan baku ikan selalu ada persaingan dan membutuhkan keberanian dalam tawar menawar untuk menentukan harga. Motivasi yang tinggi memacu wanita PIA untuk memperoleh bahan baku yang baik, karena bahan baku merupakan penentu kualitas ikan asin yang dihasilkan.

Pengalaman usaha dalam pengolahan ikan asin berhubungan sangat nyata dan positif dengan tingkat keterampilan melakukan pengolahan ikan asin $\left(0.475^{* *}\right)$.
Umumnya wanita melakukan aktivitas usahanya secara turun temurun. Tingkat keterampilan yang diperoleh wanita dalam melakukan pengolahan ikan asin tersebut merupakan pengalaman yang diwariskan orang tuanya.

Pengalaman usaha dalam pengolahan ikan asin berhubungan sangat nyata dengan Keterampilan melakukan pengeringan $\left(0.396^{*}\right)$. Wanita pengolah ikan asin yang mempunyai pengalaman usaha yang cukup lama, sangat terampil menentukan tingkat pengeringan ikan asin yang optimal sehingga layak untuk dijual.

Pendidikan berhubungan sangat nyata dengan tingkat keterampilan melakukan administrasi pembukuan keuangan $(0.449 * *)$. Pendidikan wanita pengolah umumnya rendah sampai sedang (tidak tamat $\mathrm{SD}$, dan tamat $\mathrm{SD}$ ), dan mereka umumnya kurang terampil melakukan administrasi pembukuan keuangan. Keberhasilan wanita pengolah ikan asin di Muara Angke dalam membantu ekonomi keluarga perlu ditunjang dengan tingkat keterampilan administrasi pembukuan keuangan, sehingga usaha pengolahan ikan asin yang sudah dilakukan secara turun temurun dari warisan keluarga dapat terus berkembang.

Tabel 3. Koefisien Korelasi Karakteristik Internal dengan Tingkat Keterampilan Wanita Pengolah Ikan Asin di Muara Angke

\begin{tabular}{|c|l|c|c|c|c|c|c|}
\hline \multirow{2}{*}{ No. } & \multicolumn{1}{|c|}{ Faktor Internal } & \multicolumn{7}{|c|}{ Tingkat Keterampilan } \\
\cline { 3 - 8 } & & MBBI & MPIA & MPng & MP & MAP & MIP \\
\hline 1. & Umur & 0.030 & -0.158 & -0.195 & -0.121 & 0.050 & 0.009 \\
\hline 2. & Pendidikan & 0.137 & -0.266 & -0.223 & -0.201 & $\mathbf{0 . 3 4 9}$ & 0.207 \\
\hline 3. & $\begin{array}{l}\text { Jumlah tanggungan } \\
\text { keluarga }\end{array}$ & 0.056 & -0.062 & -0.225 & 0.238 & 0.246 & 0.206 \\
\hline 4. & Pengalaman usaha & $\mathbf{0 . 3 9 2}^{* *}$ & $\mathbf{0 . 4 7 5} * *$ & $\mathbf{0 . 3 9 6}^{* *}$ & 0.241 & 0.045 & $\mathbf{0 . 3 1 7} *$ \\
\hline 5. & Motivasi & $\mathbf{0 . 4 4 4} *$ & 0.244 & 0.075 & 0.115 & 0.250 & 0.078 \\
\hline 6. & $\begin{array}{l}\text { Kesediaan menerima } \\
\text { informasi }\end{array}$ & 0.265 & 0.142 & -0.138 & 0.203 & 0.089 & 0.008 \\
\hline
\end{tabular}

Ket. $*=$ berhubungan nyata pada $\alpha=0.05$

$* *=$ berhubungan sangat nyata pada $\alpha=0.01$

MBBI = mendapatkan bahan baku ikan, MPIA = melakukan pengolahan ikan asin, $\mathrm{MPng}=$ melakukan pengeringan, $\mathrm{MP}=$ melakukan pengemasan, $\mathrm{MAP}=$ melakukan administrasi pembukuan, dan MIP = mencari informasi pasar. 
Pengalaman usaha berhubungan nyata dengan tingkat keterampilan mencari informasi pasar $\left(0.317^{*}\right)$. Semakin pengalaman seseorang, semakin banyak berinteraksi dengan pembeli-pembeli dari luar Jakarta. Pengalaman usaha yang tinggi mempunyai keterampilan dalam mencari informasi pasar, sehingga mereka dapat menjual hasil produk ikan asin ke daerahdaerah di Indonesia, ada beberapa responden yang sudah mengakses produknya untuk diekspor ke luar negeri.

\section{Hubungan Faktor Eksternal dengan Tingkat Keterampilan}

Materi penyuluhan berhubungan sangat nyata dengan lima variabel tingkat keterampilan yaitu terampil dalam melakukan pengolahan ikan asin, terampil melakukan pengeringan, terampil melakukan pengemasan, terampil melakukan administrasi pembukuan dan terampil mencari informasi pasar.
Materi

penyuluhan

akan diterima/diadopsi oleh sasaran apabila merupakan kebutuhannya, dan harus dapat memecahkan permasalahannya. Sesuai yang dikemukakan Mardikanto (1993) bahwa materi yang berisikan pemecahan masalah merupakan kebutuhan yang utama diperlukan oleh masyarakat sasaran.

Ketersediaan pasar berhubungan nyata dengan keterampilan dalam mendapatkan bahan baku ikan. Semakin tersedia pasar penjualan ikan, semakin terampil dalam mendapatkan bahan baku ikan dengan ditunjang modal yang memadai. Ketersediaan pasar mempunyai hubungan yang nyata dengan keterampilan mencari informasi pasar. Semakin tersedia pasar, makin terampil wanita pengolah ikan asin dalam mencari informasi pasar yang menguntungkan.

Tenaga kerja (curahan waktu) tidak ada keeratan dengan tingkat keterampilan wanita pengolah ikan asin. Berapapun waktu yang dibutuhkan hubungannya lemah dengan tingkat keterampilan responden.

Tabel 4. Koefisien Korelasi Faktor Eksternal dengan Tingkat Keterampilan Wanita Pengolah Ikan Asin di Muara Angke

\begin{tabular}{|c|l|c|c|c|c|c|c|}
\hline No. & Faktor Eksternal & \multicolumn{7}{|c|}{ Tingkat Keterampilan } \\
\cline { 3 - 8 } & & MBBI & MPIA & MPng & MP & MAP & MIP \\
\hline 1. & Materi penyuluhan & 0.069 & $\mathbf{0 . 3 1 8}^{*}$ & $\mathbf{0 . 3 3 7}^{*}$ & $\mathbf{0 . 3 1 7}^{*}$ & $\mathbf{0 . 3 0 8}^{*}$ & $\mathbf{0 . 3 4 0}^{*}$ \\
\hline 2. & Ketersediaan pasar & $\mathbf{0 . 3 5 1}^{*}$ & 0.011 & 0.004 & 0.070 & -0.031 & $\mathbf{0 . 3 2 8}^{*}$ \\
\hline 3. & Tenaga kerja & 0.096 & 0.043 & 0.270 & 0.006 & 0.207 & 0.255 \\
\hline
\end{tabular}

Ket. * = berhubungan nyata pada $\alpha=0.05$

$* *$ = berhubungan sangat nyata pada $\alpha=0.01$

MBBI = mendapatkan bahan baku ikan, MPIA = melakukan pengolahan ikan asin, $\mathrm{MPng}=$ melakukan pengeringan, $\mathrm{MP}=$ melakukan pengemasan, $\mathrm{MAP}=$ melakukan administrasi pembukuan, dan MIP = mencari informasi pasar.

Hubungan Tingkat Keterampilan dengan Produktivitas Usaha

Tingkat keterampilan mendapatkan bahan baku ikan berhubungan sangat nyata dengan salah satu peubah produktivitas usaha yaitu volume $(0,591 * *)$. Wanita pengolah yang terampil mendapatkan bahan baku ter- nyata menghasilkan volume produk yang cukup tinggi.

Tingkat keterampilan wanita dalam melakukan pengolahan ikan asin berhubungan nyata dengan produktivitas usaha yaitu keuntungan $\left(0,354^{*}\right)$. 
Tabel 5. Koefisien Korelasi Tingkat Keterampilan dengan Produktivitas Usaha Wanita Pengolah Ikan Asin di Muara Angke

\begin{tabular}{|c|l|c|c|}
\hline \multirow{2}{*}{ No. } & \multirow{2}{*}{$\begin{array}{c}\text { Tingkat Keterampilan Wanita } \\
\text { Pengolah Ikan Asin }\end{array}$} & \multicolumn{2}{|c|}{ Produktivitas Usaha } \\
\cline { 3 - 4 } & \multicolumn{1}{|c|}{ Volume } & Keuntungan \\
\hline 1. & Mendapatkan bahan baku ikan & $\mathbf{0 . 5 9 1 * *}$ & 0,269 \\
\hline 2. & Melakukan pengolahan ikan asin & 0,264 & $\mathbf{0 , 3 5 4}$ \\
\hline 3. & Melakukan pengeringan & 0,235 & $\mathbf{0 , 4 1 4} * *$ \\
\hline 4. & Melakukan pengemasan & 0,137 & 0,269 \\
\hline 5. & $\begin{array}{l}\text { Melakukan administrasi } \\
\text { pembukuan }\end{array}$ & 0,113 & $\mathbf{0 , 4 9 3} * *$ \\
\hline 6. & Mencari informasi pasar & $\mathbf{0 , 3 2 1} *$ & $\mathbf{0 , 4 4 0} * *$ \\
\hline
\end{tabular}

Ket. $*=$ berhubungan nyata pada $\alpha=0.05$

$* *=$ berhubungan sangat nyata pada $\alpha=0.01$

Wanita pengolah yang terampil melakukan pengolahan ikan asin lebih cepat, lebih pintar dan lebih bervariasi dalam melakukan pengolahan ikan asin.

Kualitas produk ikan asin ditentukan oleh tingkat pengeringan yang optimal. Tingkat keterampilan melakukan pengeringan berhubungan sangat nyata dengan salah satu produktivitas usaha yaitu keuntungan $(0,414 * *)$. Produk ikan asin dengan tingkat pengeringan yang optimal mempunyai kelebihan tidak mudah busuk dan tahan jamur. serta berat produk yang dihasilkan lebih optimal sehingga menguntungkan.

$\begin{array}{clr}\text { Tingkat } & \text { keterampilan melakukan } \\ \text { administrasi } & \text { pembukuan } & \text { keuangan }\end{array}$ berhubungan sangat nyata dengan keuntungan $(0,493 * *)$. Pengolah yang terampil dalam melakukan administrasi pembukuan keuangan akan dapat membedakan adalah modal dengan kebutuhan keluarga sehari-hari, dapat menghitung pengeluaran dan pemasukan, keuntungan dan kerugian.

Tingkat keterampilan mencari informasi pasar berhubungan nyata dengan volume $\left(0,321^{*}\right)$ dan berhubungan sangat nyata dengan dan keuntungan $(0,440 * *)$. Semakin tinggi tingkat keterampilan responden dalam mencari informasi pasar, maka semakin tinggi volume dan keuntungan yang dihasilkan. Apabila permintaan pasar produk ikan asin jenis komoditas tertentu sedang tinggi, maka pengolah akan memproduksi dengan volume yang tinggi produk ikan asin jenis komoditas tertentu sesuai permintaan pasar. usaha tersebut dapat berhasil kalau penguasaan pasar (jaminan pasar) ada, maka wanita pengolah yang terampil mancari informasi pasar akan memperoleh tingkat pembeli yang lebih menguntungkan.

\section{Kesimpulan}

Berdasarkan hasil analisis dan pembahasan, maka dapat disimpulkan beberapa hal sebagai berikut:

1. Tingkat pendidikan, tingkat pengalaman usaha, dan motivasi merupakan karakteristik internal wanita pengolah ikan asin yang berhubungan nyata dengan tingkat keterampilan.

2. Materi penyuluhan dan tingkat ketersediaan pasar merupakan faktor eksternal wanita pengolah ikan asin yang berhubungan nyata dengan tingkat keterampilan.

3. Tingkat keterampilan mendapatkan bahan baku, tingkat keterampilan melakukan 
pengolahan, tingkat keterampilan

melakukan pengeringan, tingkat

keterampilan melakukan administrasi

pembukuan, dan tingkat keterampilan

mencari informasi pasar merupakan tingkat keterampilan wanita pengolah ikan asin yang berhubungan nyata dengan produktivitas usaha.

\section{Rujukan}

Mardikanto. 1993. Penyuluhan Pembangunan Pertanian. Surakarta: Sebelas Maret University Press.

Prihartini, R.L. 2000. "Tingkat Motivasi Kerja Anggota Kelompok Produksi Keluarga Sejahtera (Prokesra) Usaha Peningkatan Pendapatan Keluarga Sejahtera (UPPKS) (Kasus Anggota UPPKS di Kotamadya Bogor)". Tesis pada Program Pasca Sarjana Institut Pertanian Bogor.

Pudjiwati, S. 1985. Peranan Wanita dalam Perkembangan Masyarakat Desa. Jakarta: Yayasan Ilmu-Ilmu Sosial (YIIS) dan CV. Rajawali.

Siegel, S. 1997. Statistik Non parametrik: Untuk ilmu-ilmu sosial. Jakarta: Gramedia. 